\title{
Precision biopsy of breast microcalcifications: An improvement in surgical excision
}

\author{
YOU PENG ${ }^{1}$, ZHONG-YAO LUO $^{1}$, JIE NI $^{2}$, HAI-DONG CUI ${ }^{2}$, BEI LU ${ }^{2}$, AI-ZHAI XIANG ${ }^{2}$, \\ JUN ZHOU $^{2}$, JIN-WANG DING ${ }^{1}$, WEN-HUI CHEN ${ }^{3}$, JING ZHAO $^{3}$, JIAN-HUA FANG $^{4}$ and PAN ZHAO ${ }^{5}$ \\ Departments of ${ }^{1}$ Oncological Surgery, ${ }^{2}$ General Surgery, ${ }^{3}$ Radiology, ${ }^{4}$ Ultrasound and ${ }^{5}$ Pathology, \\ Hangzhou First People's Hospital, Hangzhou, Zhejiang 310006, P.R. China
}

Received October 26, 2016; Accepted February 23, 2018

DOI: $10.3892 / 01.2018 .8787$

\begin{abstract}
The aim of the present study was to improve the conventional wire-guided localization biopsy (WGLB) of breast microcalcifications to overcome disadvantages associated with the procedure, including inaccurate localization and large specimen volume. The novel approach described in the present study was termed double wire-guided localization and rotary cutting biopsy (DWGLB). Prior to surgery, the precise localization of the lesions was assessed using two wires under the assistance of mammography X-ray and ultrasound, followed by complete excision of the lesions using a novel rotary cutting tool. The cylindrical specimen was placed on a scaled specimen holder for pathological examination. DWGLB was performed in 108 patients with the classification of as Breast Imaging Reporting and Data System score 4A. Percutaneous localization of the lesions guided by a mammography X-ray and ultrasound were successful in all 108 lesions (100\%) with one puncture attempt. The lesions were precisely excised in all of 108 patients, and included 13 malignant lesions (DCIS of breast in 7 cases, DCIS with focal invasive carcinoma in 3 cases and invasive ductal carcinoma in 3 cases). The average distance of the BARD Dualok to the lesion was $4.1 \mathrm{~mm}$; the average weight of specimens was $8.5 \mathrm{~g}$. Compared with WGLB, DWGLB offers several advantages, including more accurate localization of lesions, a more standardized biopsy method and a smaller specimen volume. DWGLB can also provide the precise position of lesions in the specimen for further pathological examination.
\end{abstract}

Correspondence to: Dr Zhong-Yao Luo, Department of Oncological Surgery, Hangzhou First People's Hospital, 261 Huansha Road, Hangzhou, Zhejiang 310006, P.R. China

E-mail: zhongyao_luo@163.com

Key words: microcalcifications lesion, double wire-guided localization and rotary cutting biopsy, 3D location of lesions in the specimen

\section{Introduction}

Breast calcification lesions are notable imaging features of early breast cancer (1). In total, 20-30\% of calcification lesions are pathologically confirmed to be of malignant breast cancer (2-4). Breast microcalcifications lesions are particularly significant for the early diagnosis of breast cancer (5). For example, the detection of $80-90 \%$ of ductal carcinoma in situ (DCIS) is attributed to the diagnostic analysis of the breast microcalcifications (6). It has been reported that the breast microcalcification lesions may be a unique positive feature of mammography X-ray imaging for patients with non-palpable disease $(7,8)$. Mammography $\mathrm{X}$-ray imaging is highly sensitive to breast microcalcifications lesions, and is therefore considered to be the gold standard of breast microcalcifications (9). However, breast microcalcifications exist in malignant and benign lesions (for example, hardening of breast disease, mammary dysplasia, hamartoma, scarring following radiotherapy, fibrocystic disease and fibroadenoma) (10). Thus, a breast biopsy is always required to identify the microcalcifications lesions.

However, breast microcalcifications lesions are non-palpable. Thus, the surgical operation of the breast microcalcifications lesions is different with that of the clinically palpable lesions. Identifying the accurate location of the microcalcification lesions is difficult, which can lead to inaccurate and/or incomplete excision, potentially resulting in misdiagnosis. Therefore, to localize the occult lesions clearly in the surgical process and excise the lesions completely, it is crucial to precisely localize the lesions prior to surgery. However, it is difficult to excise non-palpable breast lesions by established surgical biopsy. Thus, an easy, accurate, minimally invasive biopsy method is required for the breast microcalcifications lesions $(11,12)$.

In 1965, Dodd et al (13) reported a method using wire to localize the breast lesions prior to surgery. In 1976, Frank et al (14) described the localizing of breast lesions using mammography $\mathrm{X}$-ray imaging as a guide prior to the surgical excision of breast lesions for biopsy. Nowadays, the wire-guided location (WGL) biopsy method has been widely applied and is the gold standard for the biopsy of non-palpable breast lesions (15-17). In recent years, the application of vacuum-assisted breast biopsy (VABB) has reduced the 
percentage of patients that undergo conventional surgical biopsy $(18,19)$. Barranger et al $(20)$ claimed that VABB could replace WGL to become the gold standard method of biopsy of non-palpable breast lesions. However, VABB cannot excise the breast microcalcifications lesions completely. Thus, a second surgical procedure is required (21-23).

On the other hand, a major shortcoming of conventional WGL biopsy is that the wire may shift in the processes of lesion localization and removal (24), which usually leads to the incomplete excision of the lesion. It was reported that a second surgical procedure was required in $\sim 50 \%$ patients who underwent the conventional WGL biopsy method $(25,26)$. The other disadvantages involved in the conventional WGL biopsy include the large volume and irregular shape of the specimen, the breakage of breast structure, and the difficulty in localizing the lesion in the specimen for further pathological identification $(27,28)$.

To overcome the aforementioned shortcomings, the present study reports on the development of a novel precision biopsy method of breast microcalcifications based on the double wire-guided localization and rotary cutting biopsy (DWGLB). Prior to surgery, the precise localization of the lesions was assessed by using two wires under the assistance of mammography X-ray and ultrasound, followed by the complete excision of the lesions using a novel rotary cutting tool (Fig. 1; Chinese patent no., ZL 200910099174.7 ).

\section{Materials and methods}

Patients. A total of 108 mammographically detected non-palpable breast lesions in 108 patients, comprising 62 lesions on the left breast and 46 lesions on the right breast, were attempted between May 2012 and March 2014 at the department of Oncological Surgery, Hangzhou First People's Hospital (Hangzhou, China) using DWGLB. The age range of the patients was 24-69 years, with a mean age of 45.69 years. All the lesions were classified as being of Breast Imaging Reporting and Data System (BI-RADS) (29) category 4A (suspicious abnormality).

Surgical procedure. The surgical procedure included five steps. i) The 3D localization of the microcalcification was assessed by mammography using the Senographe DS Acquisition system (GE Healthcare, Chicago, IL, USA). Subsequently, a BARD Dualok (C. R. Bard, Inc., Murray Hill, NJ, USA) was inserted into the lesion and fixed. Mammographic imaging was performed mediolaterally or lateromedially to observe the position of the lesion and the BARD Dualok. Ideally, the lesion would be localized at the bifurcation of the BARD Dualok (Fig. 2). ii) Following transportation of the patients into an operating theatre, the relative position of the lesion and the BARD Dualok was further confirmed by an ultrasound scanner (MyLab Twice, Esaote SpA, Genoa, Italy). Subsequently, a mark line $(3 \mathrm{~cm})$ vertical to the BARD Dualok was made on the skin of the lesion, followed by insertion of a single hook needle vertically into the lesion. The junction point of two needles was the accurate position of the lesion (Fig. 3). iii) Local anesthesia (obtained with buffered $1 \%$ lidocaine injected into the skin and superficial tissues and with buffered $1 \%$ lidocaine

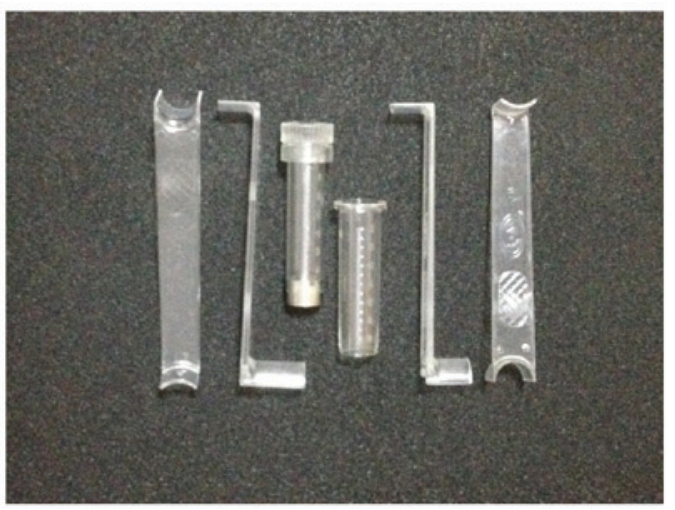

Figure 1. Rotary cutting tools (with a diameter of $2 \mathrm{~cm}$ ) used in the report (Chinese patent no. ZL 200910099174.7 )

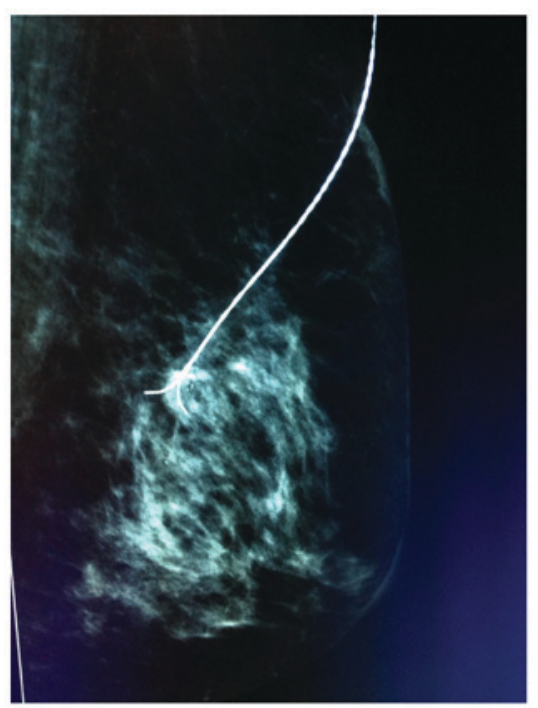

Figure 2. Example of the optimal position of the BARD Dualok shown in mammographic image. The lesion is localized at the bifurcation of the BARD Dualok (as illustrated by arrow).

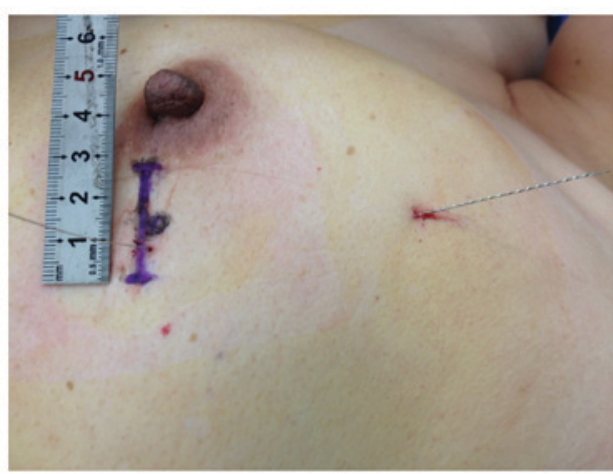

Figure 3. Image depicting a mark line $(3 \mathrm{~cm})$ vertical to the BARD Dualok made on the skin of the lesion with the assistance of an ultrasound scanner, and a single hook needle inserted vertically into the lesion. The junction point of two needles is the accurate position of the lesion.

containing epinephrine within the deeper breast tissues). iv) A 3-cm skin incision was made according to the mark line. Double wire-guided lesion sampling was performed using a rotary cutting device (Figs. 4 and 5). v) The lesion samples 


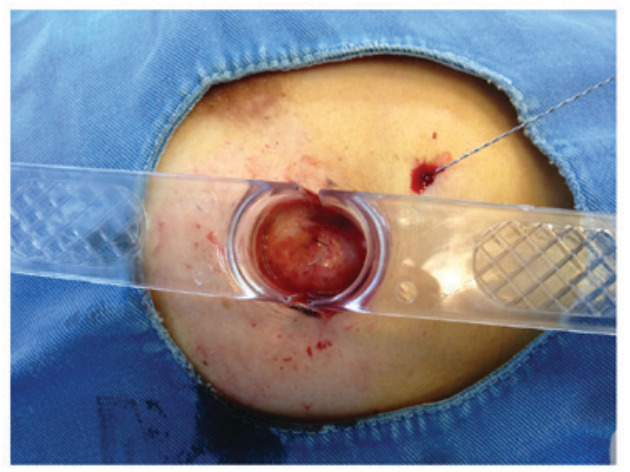

Figure 4. Image depicting a $3-\mathrm{cm}$ skin incision made according to the mark line, and exposure of the mammary gland and the single hook needle by scraping and separating the subcutaneous adipose tissue using a breast retractor.

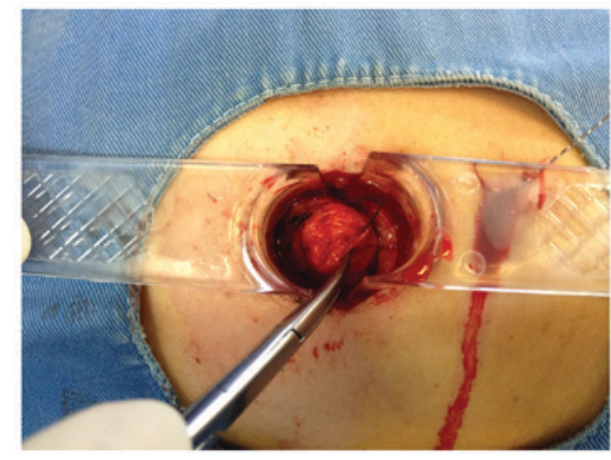

Figure 5. Image depicting the excision of the lesion. A 2-cm rotary cut tool was used to make a round cut down to the breast tissue by the center of the single hook needle. The rotary cut tool was withdrawn when it contacted to the BARD Dualok in the deep breast tissue. The lesion was completely excised using an electric knife.

were reviewed by a pathologist (Figs. 6 and 7), followed by compression and dressing of the wound if they were benign calcifications, or proceeding to further surgical excision if they were malignant lesions.

Statistical analysis. All statistical analyses were done using SPSS 19.0 (IBM Corp., Armonk, NY, USA). The association between two categorical variables was evaluated using the $\chi^{2}$ test. $\mathrm{P}<0.05$ was considered to indicate a statistically significant difference.

\section{Results}

Results of puncture localization and specimen removal. Percutaneous localization of the lesions guided by mammography and ultrasound were successful in all 108 lesions (100\%) with one puncture attempt, which is consistent with the previous studies (98-100\%) (30-32). No evident complication was observed. All 108 lesions were excised using DWGLB, with a mean distance between the needle and lesion of $4.1 \mathrm{~mm}$ (range, $0-20 \mathrm{~mm}$ ) and mean specimen weight of $8.5 \mathrm{~g}$ $(6-15 \mathrm{~g})$. The mean surgical time was $<1 \mathrm{~h}$ per biopsy. The complete excision rate of DWGLB was $100 \%$. The comparison of DWGLB with the conventional WGLB is depicted in Table I (33-35).

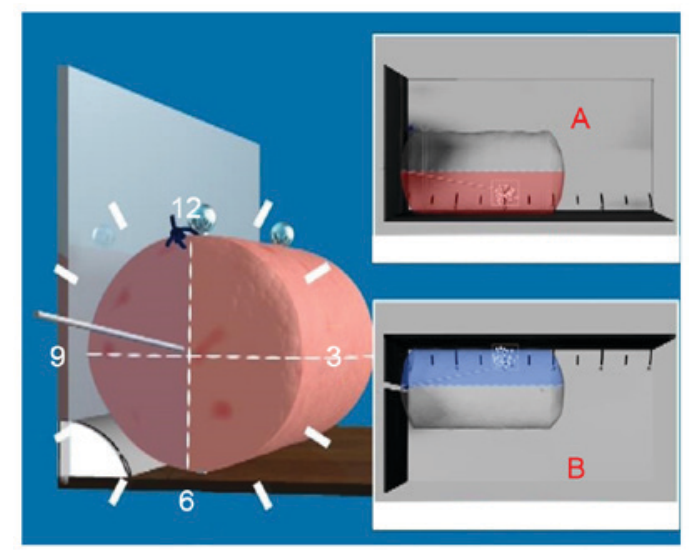

Figure 6. Schematic illustration of the specimen marked at the top side of the cylinder using a suture on a scaled specimen holder. (A) Side view of the specimen. (B) Top view of the specimen.

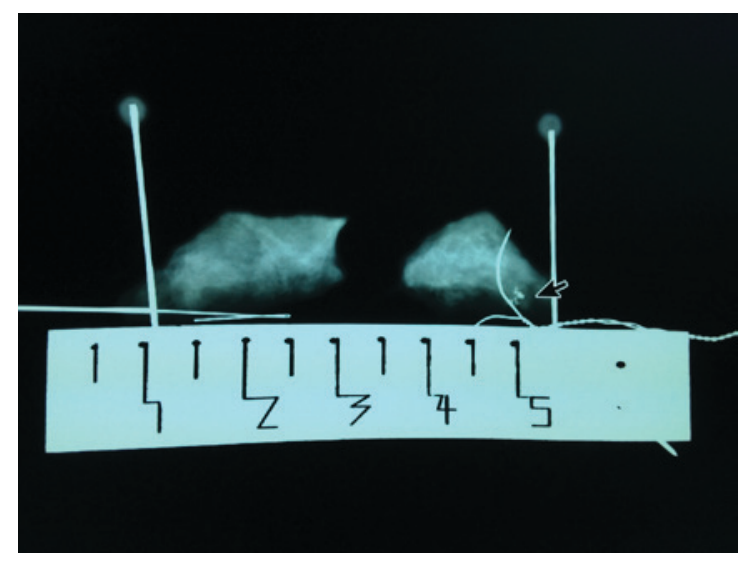

Figure 7. X-ray image of the specimen. BARD Dualok was used to provide the precise position of lesions in the specimen for further pathological examination.

Association of breast cancer detection with the position and shape of lesions. A total of 108 mammographically detected non-palpable breast lesions in 108 patients, comprising 62 lesions on the left breast and 46 lesions on the right breast, included 62 lesions with cluster distribution, 38 lesions with regional distribution/segment distribution and 8 lesions with linear distribution. In total, 13 lesions $(12.0 \%)$ were diagnosed as malignant (DCIS of breast in 7 lesions, DCIS with focal invasive carcinoma in 3 lesions and invasive ductal carcinoma in 3 lesions). There were 88 negative lesions, including 75 cases of adenosis of the breast, 10 of breast intracanalicular fibroma, 2 of intraductal papilloma and 1 of papillary hyperplasia (Table II). Of the 62 lesions with cluster distribution, breast cancer was diagnosed in 10 cases $(16.1 \%)$ by biopsy. Of the 46 lesions with non-cluster distribution, DCIS was diagnosed by biopsy in 3 cases $(6.5 \%)$ (Table III).

A total of 95 benign lesions underwent segmental mastectomy (rotation biopsy). Hematoma was observed in 2 lesions following the procedure, which disappeared following conservative treatment. No cases of active bleeding were observed. All patients with malignant lesions underwent surgery later, although none of them exhibited residual tissue at the first follow-up with mammography, including modified radical 
Table I. Comparison of DWGLB with the conventional WGLB.

\begin{tabular}{|c|c|c|c|c|c|c|c|}
\hline Study & $\begin{array}{l}\text { Localization } \\
\text { method }\end{array}$ & $\begin{array}{c}\text { Surgical } \\
\text { method }\end{array}$ & $\begin{array}{c}\text { Distance } \\
\text { between needle } \\
\text { and lesion, } \mathrm{mm}\end{array}$ & $\begin{array}{l}\text { Specimen } \\
\text { weight, g }\end{array}$ & $\begin{array}{c}\text { Patients, } \\
n\end{array}$ & $\begin{array}{c}\text { Lesion } \\
\text { localization }\end{array}$ & (Refs.) \\
\hline Mariscal Martinez et al & WGL & Surgical biopsy & $<20$ & 67.3 & 68 & Not assessed & (33) \\
\hline Rampaul et al & WGL & Surgical biopsy & $<20$ & 31 & 47 & Not assessed & (34) \\
\hline Rahusen et al & WGL & Surgical biopsy & Not assessed & 53 & 23 & Not assessed & (35) \\
\hline Present study & DWGLB & Rotary cutting biopsy & 4.1 & 8.5 & 108 & $\begin{array}{l}\text { Submillimeter } \\
\text { accuracy }\end{array}$ & - \\
\hline
\end{tabular}

WGL, wire-guided localization; DWGLB, double wire-guided localization and rotary cutting biopsy.

Table II. Clinicopathological features of patients.

\begin{tabular}{|c|c|}
\hline Variable & Patients, $\mathrm{n}$ \\
\hline \multicolumn{2}{|l|}{ Pathological diagnosis $(n=108)$} \\
\hline DCIS & 7 \\
\hline DCIS with invasive & 3 \\
\hline Invasive ductal carcinoma & 3 \\
\hline $\mathrm{ADH}$ & 7 \\
\hline Adenosis & 75 \\
\hline Fibroadenoma & 10 \\
\hline Intraductal papilloma & 2 \\
\hline Papillary hyperplasia & 1 \\
\hline \multicolumn{2}{|l|}{ Selection of operation $(n=13)$} \\
\hline Modified radical mastectomy & 7 \\
\hline $\mathrm{BCS}+\mathrm{SLNB}$ & 2 \\
\hline Mastectomy+SLNB & 4 \\
\hline \multicolumn{2}{|c|}{ Invasive carcinoma TNM staging $(n=6)$} \\
\hline IA & 4 \\
\hline IIA & 2 \\
\hline \multicolumn{2}{|l|}{ Molecular subtyping $(\mathrm{n}=6)$} \\
\hline Luminal A & 3 \\
\hline Luminal B & 1 \\
\hline Triple negative & 1 \\
\hline HER2 overexpression & 1 \\
\hline \multicolumn{2}{|c|}{ Postoperative adjuvant therapy $(n=18)$} \\
\hline Endocrinotherapy & 10 \\
\hline Chemotherapy & 3 \\
\hline Radiotherapy & 3 \\
\hline Targeted therapy & 2 \\
\hline
\end{tabular}

DCIS, ductal carcinoma in situ; ADH, atypical ductal hyperplasia; BCS, breast conservative surgery; SLNB, sentinel lymph node biopsy; HER2, human epidermal growth factor receptor 2 .

mastectomy for breast cancer in 7 cases, the breast conservation surgery plus sentinel lymph node biopsy in 2 , and the unilateral mastectomy plus sentinel lymph node biopsy in 4. In total, 10 of 13 malignant lesions following surgical operation were given the endocrinotherapy. In total, 3 patients were first given chemotherapy, followed by radiotherapy in 1 patient with the lymphatic metastasis and the targeted therapy using trastuzumab in 2 with human epidermal growth factor receptor 2 (HER2) expression. The other 2 patients with BCS underwent radiotherapy. In the follow-up period of 16-38 months, no metastasis and recurrence were identified in the 13 malignant lesions and no new tumor formation in 95 benign lesions was observed, neither.

\section{Discussion}

Breast carcinoma is the most common malignant tumor in female patients, with the second highest mortality rate (36). The early diagnosis of breast cancer significantly decreases the recurrence, metastasis and mortality rate of the disease (37-39). Breast microcalcification is a manifestation of early breast cancer; it is therefore vital to localize the lesions precisely and excise them completely for the following pathological examination and the treatment.

The distance between the needle and lesion was mostly $20 \mathrm{~mm}$ measured by the mammography (40), which further increased subsequent to releasing the pressure plate of the molybdenum target. As a result, there were usually certain residual lesions and the second surgery was needed $(15,25,41)$. To avoid shifting the needle, the needle core was pushed out of the needle sheath by $\sim 1 \mathrm{~cm}$ after the puncture needle reached to the lesion, which made the BARD Dualok insert into breast tissue from two sides. Meanwhile, the needle core was kept under pressure to cause it to continuously puncture into breast tissue whilst withdrawing the needle sheath and releasing the plate, until the breast restored itself to a natural state. It was observed that the needle could puncture the breast several $\mathrm{cm}$ deep, varying with the volume of the breast and the position of the lesion. In the series of patients in the present study, the mean distance between the needle and lesion was $4.1 \mathrm{~mm}$, and the majority of lesions were located at the bifurcation of the BARD Dualok. Thus, the precision of localization under the mammography was significantly improved compared with the previous reports, where the mean distance between the needle and lesion was $<20 \mathrm{~mm}(33,34)$.

Previous research demonstrates that detection rate of breast microcalcifications using ultrasound alone is low, and it is only $30-50 \%$ of detection rate of mammography X-ray $(42,43)$. It 
Table III. Association between breast cancer incidence and the position and shape of the lesion.

\begin{tabular}{lccr}
\hline Position and shape of lesions & Breast cancer & Benign lesions & $\chi^{2}$-value \\
\hline Left side & 7 & 55 & 0.08 \\
Right side & 6 & 40 & $>0.05$ \\
Cluster distribution & 10 & 52 & $>2.30$ \\
Non-cluster distribution & 3 & 43 & $>0.05$ \\
\hline
\end{tabular}

was reported that the combination of ultrasound and $\mathrm{X}$ ray mammography was useful to detect the non-palpable lesions and identify the breast lesions (benign or malignant) $(44,45)$. To overcome the disadvantages of conventional WGL, including inaccurate localization, difficulty for localization of the lesions (46), DWGLB utilized dual localization using mammography and ultrasound. Following the localization of microcalcifications by mammography, the patient lay in the supine position in order to achieve the flattest state of the breast. The ultrasound probe was used to detect the position of the BARD Dualok. Subsequently, a mark $3 \mathrm{~cm}$ vertical to the BARD Dualok was made on the skin of the lesion, followed by the insertion of a single hook needle vertically into the lesion. The junction point of the two needles was the accurate position of the lesion (Fig. 3). Finally, a 3-cm skin incision was made according to the mark and the lesions could be found along with the single hook needle. Compared with the conventional WGL, DWGLB could provide a more accurate localization of the lesions and substantially decrease the surgical area.

In conventional WGL, the excision of breast tissues is highly dependent on the experience of the surgeon. On the contrary, the surgical approach and the size and shape of the specimen are standardized following the dual localization using the mammography and the ultrasound: A $3 \mathrm{~cm}$ incision was first made on the skin according to the mark line, followed by scraping and separating the subcutaneous adipose tissue to expose the mammary gland and the single hook needle. In this way, the whole surgical operation could be performed only in the breast tissue. Subsequently, a 2-cm rotary cut tool was used to make a round cut down to the breast tissue by the center of the single hook needle. The rotary cut tool was withdrawn when it contacted the BARD Dualok in the deep breast tissue. The lesion was then completely excised using an electric knife by comparing of the position of lesion shown in Fig. 2 and the relative distance between the BARD Dualok and lesion shown in Fig. 5.

The specimen excised using conventional WGL is usually irregular. Thus, it is difficult for the pathologists to determine the position of the lesion in the specimen, resulting in a potential missed diagnosis (24). On the contrary, the specimen excised by using DWGLB was cylindrical breast tissue, with the top side of the cylinder marked by using a suture. The specimen was placed on a scaled specimen holder (Fig. 6), enabling the pathologists to find the lesion by pathological examination more easily. It was observed that $12 \%(13 / 108)$ of the breast microcalcifications of BI-RADS score 4A were diagnosed as early-stage breast cancer in the present study.

There is no confirmed standard yet concerning the weight of the surgically excised biopsy specimen. The guidelines of British Association of Surgical Oncology state that the weight of the specimen of at least $80.0 \%$ benign lesions excised by using wire-localization techniques should be less than $20 \mathrm{~g}$ (47). However, this goal has become difficult to achieve since the mammography screening was widely applied. The mean weight of biopsy specimen of benign lesions was $28 \mathrm{~g}$ between 1997 and 1998, with $47.0 \%$ of benign lesion biopsy specimens weighing $<20 \mathrm{~g}$ (48). In the present study, the mean weight of specimen was $<8.5 \mathrm{~g}$, which was significantly decreased compared with that of the minimum group in the previous studies (31 g) (34). Thus, the shape of the breasts was retained.

In conclusion, compared with conventional WGL, DWGLB has several advantages, including the precise localization of calcifications, the small specimen volume, the complete excision of the lesions and the increased accuracy of pathological examination. Therefore, DWGLB should be recommended for the early diagnosis and treatment of patients with breast cancer.

\section{Acknowledgements}

The authors would like to thank all other clinical trials research unit staff, past and present, who contributed to the DWGLB trial (including to trial coordination, statistical analysis, data entry and administration, and database development and support), the additional members of the trial management group, the trial steering committee for their notable contributions.

\section{Funding}

The present study was funded by the Science and Technology Department of Zhejiang Province (grant no. 2010 C33097) and Technology Bureau of Hangzhou City (grant no. 20100633B02 and 20160533B12).

\section{Availability of data and materials}

All data or analyzed during this study are included in this published article.

\section{Author's contributions}

ZYL contributed to trial design and protocol development. YP performed statistical analysis, drafted the report and approved the final version of the article. WHC, JiZ, JHF and PZ contributed to mammography, ultrasound, pathological diagnosis and data monitoring. JN was involved in the surgical biopsy and postoperative data management and was involved in revising the manuscript critically for important intellectual 
content. HDC and BL collected and verified all data. AZX, JuZ and JWD analyzed and interpreted the results.

\section{Ethics approval and consent to publish}

This clinical trial was approved by Hangzhou First People's Hospital Ethics Committee (approval number: 2010-004-01). The trial was registered with the Chinese Clinical Trial Registry (registration number: ChiCTR-DDT-14004231).

\section{Consent for publication}

All participants gave informed consent for publication of any associated data and accompanying images were obtained from all subjects.

\section{Competing interests}

The authors declare that they have no competing interests.

\section{References}

1. Tabár L and Dean PB: Teaching atlas of mammography. Fortschr Geb Rontgenstrahlen Nuklearmed Erganzungsbd 116: 1-222, 2001.

2. Craft M, Bicknell AM, Hazan GJ and Flegg KM: Microcalcifications detected as an abnormality on screening mammography: Outcomes and followup over a five-year period. Int J Breast Cancer 2013: 458540, 2013.

3. Bent CK, Bassett LW, D'Orsi CJ and Sayre JW: The positive predictive value of BI-RADS microcalcification descriptors and final assessment categories. AJR Am J Roentgenol 194: 1378-1383, 2010.

4. Lazarus E, Mainiero MB, Schepps B, Koelliker SL and Livingston LS: BI-RADS lexicon for US and mammography: Interobserver variability and positive predictive value. Radiology 239: 385-391, 2006

5. Naseem M, Murray J, Hilton JF, Karamchandani J, Muradali D, Faragalla H, Polenz C, Han D, Bell DC and Brezden-Masley C: Mammographic microcalcifications and breast cancer tumorigenesis: A radiologic-pathologic analysis. BMC Cancer 15: 307, 2015.

6. Evans A, Pinder S, Wilson R, Sibbering M, Poller D, Elston C and Ellis I: Ductal carcinoma in situ of the breast: Correlation between mammographic and pathologic findings. AJR Am J Roentgenol 162: 1307-1311, 1994.

7. Bassett LW: Mammographic analysis of calcifications. Radiol Clin North Am 30: 93-105, 1992.

8. Fondrinier E, Lorimier G, Guerin-Boblet V, Bertrand AF, Mayras C and Dauver N: Breast microcalcifications: Multivariate analysis of radiologic and clinical factors for carcinoma. World $\mathrm{J}$ Surg 26: 290-296, 2002.

9. Sick A: Mammographic detestability of breast microcalcifications. AJR 1399: 231-236, 1982.

10. Barman I, Dingari NC, Saha A, McGee S, Galindo LH, Liu W, Plecha D, Klein N, Dasari RR and Fitzmaurice M: Application of Raman spectroscopy to indentify microcalcifications and underlying breast lesions at stereotactic core needle biopsy. Cancer Res 73: 3206-3215, 2013.

11. Ohsumi S, Taira N, Takabatake D, Takashima S, Hara F, Takahashi M, Kiyoto S, Aogi K and Nishimura R: Breast biopsy for mammographically detected nonpalpable lesions using a vacuum-assisted biopsy device (Mammotome) and upright-type stereotactic mammography unit without a digital imaging system: Experience of 500 biopsies. Breast Cancer 21: 123-127, 2014.

12. Fusco R, Petrillo A, Catalano O, Sansone M, Granata V, Filice S, D'Aiuto M, Pankhurst Q and Douek M: Procedures for location of non-palpable breast lesions: A systematic review for the radiologist. Breast Cancer 21: 522-531, 2014.

13. Dodd G, Fry K and Delany W: Pre-operative localization of occult carcinoma of the breast. In: Management of the patient with cancer. Nealon TF (ed). Saunders, Philadelphia, PA, pp88-113, 1965.
14. Frank HA, Hall FM and Steer ML: Preoperative localization of nonpalpable breast lesions demonstrated by mammography. N Engl J Med 295: 259-260, 1976.

15. Burkholder HC, Witherspoon LE, Burns RP, Horn JS and Biderman MD: Breast surgery techniques: Preoperative bracketing wire localization by surgeons. Am Surg 73: 574-578, 2007.

16. Kouskos E, Gui GP, Mantas D, Revenas K, Rallis N, Antonopoulou Z, Lampadariou E, Gogas H and Markopoulos C: Wire localisation biopsy of non-palpable breast lesions: Reasons for unsuccessful excision. Eur J Gynaecol Oncol 27: 262-266, 2006.

17. Jackman RJ and Marzoni FA Jr: Needle-localized breast biopsy: Why do we fail? Radiology 204: 677-684, 1997.

18. Kettritz U, Rotter K, Schreer I, Murauer M, Schulz-Wendtland R, Peter D and Heywang-Köbrunner SH: Stereotactic vacuum-assisted breast biopsy in 2874 patients: A multicenter study. Cancer 100: 245-251, 2004.

19. Agacayak F, Ozturk A, Bozdogan A, Selamoglu D, Alco G, Ordu C, Pilanci KN, Killi R and Ozmen V: Stereotactic vacuum-assisted core biopsy results for non-palpable breast lesions. Asian Pac J Cancer Prev 15: 5171-5174, 2014.

20. Barranger E, Marpeau O, Chopier J, Antoine M and Uzan S: Site-select procedure for non-palpable breast lesions: Feasibility study with a 15-mm cannula. J Surg Oncol 90: 14-19, 2005.

21. Park HL and Kim LS: The current role of vacuum assisted breast biopsy system in breast disease. J Breast Cancer 14: 1-7, 2011.

22. Abbate F, Cassano E, Menna S and Viale G: Ultrasound-guided vacuum-assisted breast biopsy: Use at the European institute of oncology in 2010. J Ultrasound 14: 177-181, 2011.

23. Youn I, Kim MJ, Moon HJ and Kim EK: Absence of residual microcalcifications in atypical ductal hyperplasia diagnosed via stereotactic vacuum-assisted breast biopsy: Is surgical excision obviated? J Breast Cancer 17: 265-269, 2014.

24. Ocal K, Dag A, Turkmenoglu O, Gunay EC, Yucel E and Duce MN: Radioguided occult lesion localization versus wire-guided localization for non-palpable breast lesions: Randomized controlled trial. Clinics (Sao Paulo) 66: 1003-1007, 2011.

25. Fleming FJ, Hill AD, Mc Dermott EW, O'Doherty A, O'Higgins NJ and Quinn CM: Intraoperative margin assessment and re-excision rate in breast conserving surgery. Eur J Surg Oncol 30: 233-237, 2004.

26. Postma EL, Witkamp AJ, van den Bosch MA, Verkooijen HM and van Hillegersberg R: Localization of nonpalpable breast lesions. Expert Rev Anticancer Ther 11: 1295-1302, 2011.

27. Staradub VL, Rademaker AW and Morrow M: Factors influencing outcomes for breast conservation therapy of mammographically detected malignancies. J Am Coll Surg 196: 518-524, 2003.

28. Medina-Franco H, Abarca-Pérez L, García-Alvarez MN, Ulloa-Gómez JL, Romero-Trejo C and Sepúlveda-Méndez J: Radioguided occult lesion localization (ROLL) versus wire-guided lumpectomy for non-palpable breast lesions: A randomized prospective evaluation. J Surg Oncol 97: 108-111, 2008.

29. Liberman L and Menell JH: Breast imaging reporting and data system (BI-RADS). Radiol Clin North Am 40: 409-430, 2002.

30. Lovrics PJ, Goldsmith CH, Hodgson N, McCready D, Gohla G, Boylan C, Cornacchi S and Reedijk M: A multicentered, randomized, controlled trial comparing radioguided seed localization to standard wire localization for nonpalpable, invasive and in situ breast carcinomas. Ann Surg Oncol 18: 3407-3414, 2011.

31. Rissanen TJ, Mäkäräinen HP, Mattila SI, Karttunen AI, Kiviniemi HO, Kallioinen MJ and Kaarela OI: Wire localized biopsy of breast lesions: A review of 425 cases found in screening or clinical mammography. Clin Radiol 47: 14-22, 1993.

32. Vrieling C, Collette L, Fourquet A, Hoogenraad WJ, Horiot JH, Jager JJ, Pierart M, Poortmans PM, Struikmans H, Maat B, et al: The influence of patient, tumor and treatment factors on the cosmetic results after breast-conserving therapy in the EORTC 'boost vs. no boost' trial. EORTC radiotherapy and breast cancer cooperative groups. Radiother Oncol 55: 219-232, 2000.

33. Mariscal Martinez A, Solà M, de Tudela AP, Julián JF, Fraile M, Vizcaya S and Fernández J: Radioguided localization of nonpalpable breast cancer lesions: Randomized comparison with wire localization in patients undergoing conservative surgery and sentinel node biopsy. AJR Am J Roentgenol 193: 1001-1009, 2009. 
34. Rampaul RS, Bagnall M, Burrell H, Pinder SE, Evans AJ and Macmillan RD: Randomized clinical trial comparing radioisotope occult lesion localization and wire-guided excision for biopsy of occult breast lesions. Br J Surg 91: 1575-1577, 2004.

35. Rahusen FD, Bremers AJ, Fabry HF, van Amerongen AH, Boom RP and Meijer S: Ultrasound-guided lumpectomy of nonpalpable breast cancer versus wireguided resection: A randomized clinical trial. Ann Surg Oncol 9: 994-998, 2002.

36. Siegel R, Ma J, Zou Z and Jemal A: Cancer statistics, 2014. CA Cancer J Clin 64: 9-29, 2014

37. Youlden DR, Cramb SM, Dunn NA, Muller JM, Pyke CM and Baade PD: The descriptive epidemiology of female breast cancer: An international comparison of screening, incidence, survival and mortality. Cancer Epidemiol 36: 237-248, 2012.

38. Paap E, Holland R, den Heeten GJ, van Schoor G, Botterweck AA, Verbeek AL and Broeders MJ: A remarkable reduction of breast cancer deaths in screened versus unscreened women: A case-referent study. Cancer Causes Control 21: $1569-1573,2010$

39. Tabár L, Vitak B, Chen TH, Yen AM, Cohen A, Tot T, Chiu SY Chen SL, Fann JC, Rosell J, et al: Swedish two-county trial: Impact of mammographic screening on breast cancer mortality during 3 decades. Radiology 260: 658-663, 2011.

40. Tinnemans JG, Wobbes T, Hendriks JH, van der Sluis RF, Lubbers EJ and de Boer HH: Localization and excision of nonpalpable breast lesions. A surgical evaluation of three methods. Arch Surg 122: 802-806, 1987.

41. Lovrics PJ, Cornacchi SD, Farrokhyar F, Garnett A, Chen V, Franic S and Simunovic M: The relationship between surgical factors and margin status after breast conservation surgery for early stage breast cancer. Am J Surg 197: 740-746, 2009.
42. Moon WK, Im JG, Koh YH, Noh DY and Park IA: US of mammographically detected clustered microcaleifications. Radiology 217: 849-854, 2000

43. Yu PC, Lee YW, Chou FF, Wu SC, Huang CC, Ng SH, Sheen-Chen SM and Ko SF: Clustered microcalcifications of intermediate concern detected on digital mammography: Ultrasound assessment. Breast 20: 495-500, 2011.

44. Boonlikit S: Comparison of mammography in combination with breast ultrasonography versus mammography alone for breast cancer screening in asymptomatic women. Asian Pac J Cancer Prev 14: 7731-7736, 2013.

45. Köhler J, Krause B, Grunwald S, Thomas A, Köhler G, Schwesinger G, Schimming A, Jäger B, Paepke S and Ohlinger R: Ultrasound and mammography guided wire marking of non-palpable breast lesions: analysis of 741 cases. Ultraschall Med 28: 283-290, 2007.

46. Saarela AO, Rissanen TJ, Lähteenmäki KM, Soini Y, Haukipuro K, Kaarela O and Kiviniemi HO: Wire-guided excision of non-palpable breast cancer: Determinants and correlations between radiologic and histologic margins and residual disease in re-excisions. Breast 10: 28-34, 2001.

47. Sauven P, Bishop H, Patnick J, Walton J, Wheeler E, Lawrence G; National Health Service Breast Screening Programme; British Association of Surgical Oncology: The national health service breast screening programme and British association of surgical oncology audit of quality assurance in breast screening 1996-2001. Br J Surg 90: 82-87, 2003.

48. Blamey RW: The British association of surgical oncology guidelines for surgeons in the management of symptomatic breast disease in the UK (1998 revision). BASO Breast Specialty Group. Eur J Surg Oncol 24: 464-476, 1998. 